PENELITIAN

\title{
Efektivitas midazolam untuk pencegahan mual muntah pascabedah pada prosedur laparaskopi.
}

\section{The effectiveness of the midazolam for prevention of postoperative nausea vomiting on laparascopic procedures.}

\author{
Jamiludin $\triangle^{*}$, Husain $A A A *$ \\ *Bagian ilmu anestesi, perawatan intensif dan manajemen nyeri FK UNHAS \\ $₫$ Korespondensi/correspondence: jamiluddin81@gmail.com
}

\begin{abstract}
Background: All patients undergoing surgery are at risk for experiencing postsurgical nausea and vomiting ( PONV ). The occurrence of PONV be very detrimental symptoms especially after ambulatory surgical procedures and interfere with the process of recovering from anesthesia and surgery to extend treatment time. Laparoscopy is a minimally invasive surgical procedure that accompanied high enough incidence of PONV. Causes high incidence of PONV in surgery laparaskopi caused by the gas used to insuflasi and led to an emphasis on the nervus vagus which has a relationship with vomiting center in medulla oblongata. In addition, other causes such as anesthetic technique, sex, pain, post- operative care and patient demographic data relating to the influence of the occurrence of emesis.
\end{abstract}

We evaluated the grant of midazolam as an agent as well as anti-emetics which anxiolisis also by reducing the synthesis, release and post- synaptic effects of dopamine and adenosine reuptake menhambat, to reduce the input of dopamine and 5 -HT3 against CRTZ and reduce the input from the thalamus directly influence the vomiting center .

Methods: Forty-eight patients who will undergo elective surgical procedures laparaskopi randomly divided into two groups. Having given medication premedikasi, group $M(n=24)$ given midazolam $35 \mathrm{~g} / \mathrm{kg}$ body weight intravenously; groups $O$ ( $n$ $=24$ ) given ondansetron $4 \mathrm{mg}$ intravenously. Procedures for anesthesia, opioid usage and long operation recorded. Then post- surgical nausea, vomiting incident was observed and recorded over a period of 8 hours postoperative.

Results: The occurrence of nausea, vomiting after surgical procedures laparoscopic in this study are measured using PONV score with a 30-minute interval during the recovery room and every 1 hour in a treatment room for 8 hours post-surgery. At this done, there is a meaningful difference between the two groups with the result $p=$ 0.022 ( $p<0.05$ ) at P2 observation ( 60 minutes post-surgery ). 
Conclusion: midazolam $35 \mathrm{~g} / \mathrm{kg}$ body weight after premedikasi on general anesthesia in elective surgical procedures laparaskopi reduce nausea vomiting incident postoperative especially at 1 hour post-surgery.

Keywords: midazolam, ondansetron, vomiting center, post- surgical nausea vomiting, laparaskopi.

\section{ABSTRAK}

Latar belakang: Seluruh pasien yang menjalani pembedahan beresiko untuk mengalami mual dan muntah pasca bedah (PONV). Kejadian PONV menjadi gejala yang sangat merugikan terutama setelah prosedur pembedahan ambulatori serta mengganggu proses pemulihan pasca anestesi dan pembedahan sehingga memperpanjang waktu perawatan. Laparoskopi adalah suatu prosedur pembedahan minimal invasif yang disertai insidens PONV cukup tinggi. Penyebab tingginya angka kejadian PONV pada pembedahan laparaskopi disebabkan oleh gas yang digunakan untuk insuflasi dan menyebabkan penekanan pada nervus vagus yang memiliki hubungan dengan pusat muntah di medulla oblongata. Selain itu, penyebab lain seperti teknik anestesi, jenis kelamin, nyeri, perawatan pasca operatif dan data demografik pasien yang berhubungan dengan pengaruh terjadinya emesis.

Kami mengevaluasi pemberian midazolam sebagai agen anti emetik dimana selain sebagai anxiolisis juga dengan menurunkan sintesis, pelepasan dan efek pasca sinaptik dopamin serta menhambat reuptake adenosin, sehingga menurunkan input dopamin dan 5-HT3 terhadap CRTZ dan mengurangi input dari thalamus yang mempengaruhi langsung pusat muntah.

Metode: Empat puluh delapan pasien yang akan menjalani prosedur pembedahan laparaskopi elektif secara acak dibagi menjadi dua kelompok. Setelah diberikan obat premedikasi, kelompok $M(n=24)$ diberikan midazolam $35 \mu g / k g B B$ intravena; kelompok $O(n=24)$ diberikan ondansetron $4 \mathrm{mg}$ intravena. Selama prosedur anestesi, pemakaian opioid dan lama operasi dicatat. Kemudian kejadian mual muntah pasca bedah diamati dan dicatat selama periode 8 jam pascabedah.

Hasil: Kejadian mual muntah setelah prosedur pembedahan laparaskopi pada penelitian ini diukur menggunakan skor PONV dengan interval 30 menit selama di ruang pemulihan dan setiap 1 jam di ruang perawatan selama 8 jam pasca bedah. Pada penilitian ini, terdapat perbedaan yang bermakna diantara kedua kelompok dengan hasil $p=0,022$ ( $p<0,05)$ pada waktu pengamatan P2 (60 menit pasca bedah).

Kesimpulan: Midazolam $35 \mu \mathrm{g} / \mathrm{kgBB}$ setelah premedikasi pada anestesi umum pada prosedur pembedahan laparaskopi elektif menurunkan kejadian mual muntah pascabedah terutama pada 1 jam pasca bedah. 
Kata kunci: Midazolam, ondansetron, pusat muntah, mual muntah pasca bedah, laparaskopi.

\section{PENDAHULUAN}

Seluruh pasien yang menjalani pembedahan beresiko untuk mengalami mual dan muntah pasca bedah (PONV). Didefinisikan sebagai adanya trias tanda dan gejala, dimana meliputi tidak hanya keluhan fisik seperti muntah dan retching tetapi juga perasaan subyektif yang tidak menyenangkan berupa mual yang dirasakan oleh pasien dimana dapat terjadi pada periode dalam 24 jam setelah menjalani pembedahan. ${ }^{1,2,3}$

Laparoskopi adalah suatu prosedur pembedahan minimal invasif yang memungkinkan akses endoskopik ke dalam rongga peritoneum setelah insuflasi gas karbon dioksida $\left(\mathrm{CO}_{2}\right)$. Insidensi terjadinya PONV sekitar 53\% pada keseluruhan kasus yang menjalani laparaskopi cholecystektomi.

Pemanjangan durasi pembedahan dan anestesi juga memberikan andil untuk terjadinya PONV. Selain itu terdapat faktor pasca pembedahan yang meningkatkan insidensi terjadinya PONV seperti nyeri, dizzines, ambulasi dan asupan oral lebih awal serta penggunaan opioid pascabedah., ${ }^{4,5,6}$

Berbagai obat dengan mekanisme kerja berbeda, telah digunakan untuk mencegah dan mengatasi terjadinya PONV. Midazolam yang merupakan golongan benzodiazepin, juga telah diteliti untuk pencegahan dan terapi terjadinya PONV. Mekanisme midazolam yang bekerja sebagai anti emetik secara menyeluruh masih belum diketahui secara pasti. Anti emetik midazolam mungkin adalah bekerja pada chemoreseptor trigger zone (CRTZ) dengan menurunkan sintesis, pelepasan dan efek pasca sinaptik dopamin. ${ }^{7,8,9,10}$

Pada beberapa tahun terakhir, midazolam dilaporkan terbukti efektif sebagai profilaksis PONV setelah pembedahan strabismus pada pasien pediatrik, pembedahan bypass kardiopulmonar (CPB), pembedahan abdominal bawah dengan anestesi umum, bedah myringoplasty dan pada pasien pasca bedah yang mendapat patient controlled analgesia (PCA) menggunakan fentanyl. ${ }^{11,12,13,14,15}$

Dengan latar belakang diatas dan mengacu pada penelitian sebelumnya maka peneliti ingin mengevaluasi efektivitas pemberian midazolam $35 \mu \mathrm{g} /$ $\mathrm{kgBB}$ intravena dibandingkan dengan ondansetron $4 \mathrm{mg}$ intravena sebagai pencegahan PONV pada prosedur laparoskopi.

\section{METODE}

Setelah mendapatkan persetujuan komite etik Universitas Hasanuddin, penelitian dilakukan pada 48 pasien yang akan menjalani prosedur pembedahan 
laparaskopi elektif selama bulan JuniJuli 2013. Pasien yang akan menjalani prosedur bedah laparoskopi elektif dengan prosedur anestesi umum inhalasi, usia 18-60 tahun, IMT 18 - 30, PS ASA 1 dan 2, setuju ikut serta dalam penelitian dan menandatangani surat persetujuan penelitian serta ada persetujuan dari dokter primer yang merawat dimasukkan kedalam penelitian.

Kriteria ekslusi meliputi pasien dengan penyakit kardiovaskular, pasien riwayat penyakit serebrovaskular, diabetes mellitus, penggunaan steroid lama, pemberian anti histamin, steroid atau obat-obatan psikoaktif selama 24 jam sebelum pembedahan, konsumsi alkohol dan penyalahgunaan obatobatan, mendapat medikasi anti emetik 24 jam sebelum pembedahan, IMT > 30, dan wanita hamil. Lama operasi $>2$ jam dan perubahan prosedur menjadi laparotomi merupakan kriteria drop out penelitian.

Pasien secara acak dibagi dua kelompok. Kelompok perlakuan ( $\mathrm{P}$ ) yaitu kelompok yang mendapatkan midazolam $35 \mu \mathrm{g} / \mathrm{kgBB}$ intravena dan kelompok kontrol ( $\mathrm{K}$ ) yaitu kelompok yang mendapatkan ondansetron $4 \mathrm{mg}$ intravena. Semua obat dilarutkan dengan normal saline $5 \mathrm{ml}$.

Penderita yang memenuhi kriteria penelitian, tidak mendapat premedikasi di ruangan. Di kamar operasi, pasien dipasang alat pemantauan rutin seperti EKG, tekanan darah non invasif, pulse oxymetri $\left(\mathrm{SpO}_{2}\right)$, dan end tidal $\mathrm{CO}_{2}$ $\left(\mathrm{EtCO}_{2}\right)$. Diberikan premedikasi ranitidin $50 \mathrm{mg}$, deksametason $50 \mu \mathrm{g} /$ $\mathrm{kgBB}$ dan fentanyl $2 \mu \mathrm{g} / \mathrm{kgBB}$. Dilakukan pengukuran hemodinamik sebelum induksi yang ditetapkan (T0). Pasien kelompok $\mathrm{P}$ mendapatkan midazolam $35 \mu \mathrm{g} / \mathrm{kgBB}$ dan kelompok $\mathrm{K}$ mendapatkan ondansetron $4 \mathrm{mg}$. Induksi dengan propofol $1,5 \mathrm{mg} / \mathrm{kgBB}$, pelumpuh otot dengan atracurium 0,5 $\mathrm{mg} / \mathrm{kgBB}$ dan lidokain 1,5 mg/kgBB untuk menekan hemodinamik tindakan laringoskopi. Pipa nasogastrik diinsersikan setelah tindakan intubasi. Tekanan insuflasi gas $\mathrm{CO} 2$ dipertahankan 12-15mmHg. Pemeliharaan anestesi dengan inhalasi isofluran 1 volume\%, oksigen 4-5 1/ menit, fentanyl $1 \mu \mathrm{g} / \mathrm{kg} / \mathrm{jam} /$ syringe pump, atracurium $0,1 \mathrm{mg} / \mathrm{kg} / 30$ menit. EtCO2 dipertahankan 30-45 mmHg. Selama operasi, cairan ringer laktat diberikan dengan kecepatan $4 \mathrm{ml} / \mathrm{kg} / \mathrm{jam}$ (10 kgBB pertama), $2 \mathrm{ml} / \mathrm{kg} / \mathrm{jam}$ (10-20 $\mathrm{kgBB}$ ) dan $1 \mathrm{ml} / \mathrm{kg} / \mathrm{jam}$ (> $20 \mathrm{kgBB}$ ). Pengukuran hemodinamik setiap 3 menit selama operasi. Bila laju jantung dan tekanan arteri rerata meningkat lebih dari $25 \%$ dari T0, diberikan rescue analgetik fentanyl $1 \mu \mathrm{g} / \mathrm{kgBB}$. Pemberian fentanyl dapat diulang sampai maksimal $2 \mu \mathrm{g} / \mathrm{kgBB}$. Bila terjadi bradikardi (laju jantung < 50 kali/ menit), maka diberikan sulfas atropin 0,5 mg. Bila terjadi hipotensi (tekanan arteri rerata $<60 \mathrm{mmHg}$ ), diberikan ephedrine dosis 5-10 mg. Fentanyl dan isofluran dihentikan saat akhir operasi. Parasetamol 1 gr intravena diberikan 
setelah ekstubasi sebagai kontrol nyeri pascabedah. Skor PONV diobservasi pada 30 menit (P1), 60 menit (P2), 90 menit (P3), 120 menit (P4) pascabedah di ruang pemulihan, 3 jam (P5), 4 jam (P6), 5 jam (P7) dan 6 jam (P8) pasca pembedahan di ruang perawatan. Efek samping berupa perbedaan skor sedasi dinilai pada 30 menit (P1), 60 menit (P2), 90 menit (P3), 120 menit (P4) pascabedah di ruang pemulihan. Bila terjadi muntah $\geq 2$ kali dalam 30 menit atau mual menetap selama 15 menit diberikan anti emetik tambahan berupa ondansetron $4 \mathrm{mg}$ intravena. Kemudian dilakukan pengumpulan dan analisa data.

Analisa statistik dilakukan dengan piranti statistik computerized (SPSS). Variabel numerik dengan distribusi normal kedua kelompok diuji dengan Student's independent sample t-test, variabel numerik dengan distribusi tidak normal diuji dengan Mann Whiney $U$ test. Variabel kategorikal kedua kelompok diuji dengan Chi square test dan Fisher test. Nilai $P<0,05$ dinyatakan bermakna secara statistik.

\section{HASIL}

Karakteristik sampel dikedua kelompok berdasarkan usia, klasifikasi status fisik (ASA PS), jenis kelamin, IMT dan lama operasi tidak berbeda secara signifikan (tabel 1,2 dan tabel 3).

Berdasarkan tabel 4,5 dan 6, tidak terdapat perbedaan yang bermakna pada tekanan arteri rerata, laju jantung dan kebutuhan fentanyl pada kelompok ondansetron dan kelompok midazolam dimana pada semua waktu pengukuran didapatkan nilai $\mathrm{p}>0,05$.

Kejadian mual muntah setelah prosedur pembedahan laparaskopi pada penelitian ini diukur menggunakan skor PONV. Seperti tampak pada tabel 7, pengamatan kejadian PONV ini dilakukan dengan interval 30 menit selama di ruang pemulihan dan setiap 1 jam di ruang perawatan selama 8 jam pasca bedah. Pada penilitian ini, terdapat perbedaan yang bermakna diantara kedua kelompok dengan hasil nilai $\mathrm{p}=0,022 \quad(\mathrm{p}<0,05) \quad$ pada waktu pengamatan $\mathrm{P} 2$.

Perbandingan skor sedasi padakedua kelompok menggunakan skor ramsay tampak pada tabel 10. Interval pengamatan 30 menit di ruang pemulihan. Tidak terdapat perbedaan yang bermakna diantara kedua kelompok dengan hasil $\mathrm{p}>0,05$.

\section{PEMBAHASAN}

Seluruh pasien yang menjalani pembedahan beresiko untuk mengalami PONV. Mual dengan atau tanpa disertai muntah, memberikan konstribusi terhadap penundaan discharge pasien pasca anestesi. ${ }^{2,5}$

Pusat muntah di medulla oblongata, bertanggung jawab terhadap kontrol dan koordinasi mual dan muntah. Pusat muntah dapat diaktifkan ketika menerima input aferen dari traktus gastrointestinal, korteks serebral dan 
thalamus (anxietas dan nyeri), sistem vestibuler dan CRTZ. Kurang lebih 40 neurotransmiter dari pusat muntah ikut terlibat, namun hanya beberapa yang memegang peranan penting yaitu asetilkolin, histamin, dopamin dan 5HT3 (5-Hydroxytriptamin) Aplikasi obat-obat yang dapat mengantagonis zat -zat ini mempunyai efek sentral terhadap terjadinya PONV. ${ }^{16,17,18,19}$

Etiologi PONV bersifat multifaktorial seperti faktor pasien, pre operatif, intra operatif dan post operatif. Faktor resiko harus diidentifikasi yang menentukan pemberian profilaksis. Pasien dengan resiko PONV sedang dan tinggi dipertimbangkan penggunaan kombinasi. Tidak ada obat yang terbukti secara efektif dapat sepenuhnya memblok semua jalur ke arah pusat muntah. ${ }^{20,21,22,23}$

Laparoskopi adalah suatu prosedur minimal invasif dengan insidens terjadi PONV cukup tinggi akibat insuflasi rongga abdomen yang menyebabkan tekanan pada nervus vagus, dimana terdapat hubungan dengan pusat muntah di medulla oblongata. Selain penyebab lain seperti teknik anestesi, jenis kelamin, nyeri, perawatan pasca operatif berhubungan dengan pengaruh terjadinya emesis. ${ }^{24,25,26}$

Ondansetron merupakan golongan antagonis reseptor 5-HT3 yang disintesa oleh neuron serotonergik di susunan saraf pusat dan sel enterokromafin di traktus gastrointestinal sehingga efektif sebagai anti emetik. Komplikasi ondansetron adalah dapat meningkatkan resiko pemanjangan dari interval QT yang beresiko terjadinya Torsade de Pointes pada pasien yang mempunyai riwayat kelainan jantung seperti sindrom pemanjangan interval QT kongenital, pasien dengan hipokalemia dan hipomagnesia dan yang mendapat terapi obat-obatan yang dapat menyebabkan pemanjangan interval QT. ${ }^{27,28,29,30}$

Midazolam merupakan golongan benzodiazepin larut dalam air, mempunyai afinitas terhadap reseptor benzodiazepin sekitar dua kali lebih kuat dari diazepam. Digunakan secara luas sebelum tindakan anestesi untuk menghilangkan kecemasan dan menghasilkan amnesia. Pada beberapa tahun terakhir, midazolam dilaporkan terbukti efektif sebagai profilaksis PONV dengan pemberian bolus sebelum atau sesudah induksi anestesi atau diberikan secara kontinu pasca operasi. $^{26,31}$

Efek antiemetik midazolam karena bekerja pada CRTZ dengan menurunkan sintesis, pelepasan dan efek pasca sinaptik dopamin. Benzodiazepin mengurangi pelepasan dopamin secara sentral atau dengan melakukan hambatan terhadap re-uptake dari adenosin yang menyebabkan pelepasan dopamin yang dimediasi oleh adenosin. Adenosin reseptor agonis juga menghasilkan inhibisi terhadap nigrostriatal melepaskan dopamin dan reuptake adenosin terhadap sinaptosom kortikal. Adenosin, juga menurunkan 
Tabel 1. Perbandingan rerata umur, IMT, lama operasi dan ASA PS pada kedua kelompok

\begin{tabular}{lccccccc}
\hline \multirow{2}{*}{ Variabel } & \multicolumn{3}{c}{ Ondansetron } & \multicolumn{5}{c}{ Midazolam } & \multirow{2}{*}{ M } \\
& n & Mean & SD & n & Mean & SD & \\
\hline \multirow{2}{*}{ Umur } & 2 & \multirow{2}{*}{36.21} & 10.974 & 2 & 42.21 & 12.860 & \multirow{2}{*}{0.089} \\
& 4 & & & 4 & & & \\
IMT & 2 & 21.78 & 1.438 & 2 & 22.07 & 1.330 & 0.463 \\
Lama & 4 & & & 4 & & & \\
operasi & 2 & 78.79 & 24.730 & 2 & 82.04 & 21.936 & 0.632 \\
\hline
\end{tabular}

*Uji T test, bermakna bila nilai $\mathrm{p}<0,05$

Tabel 2. Perbandingan sebaran jenis kelamin pada kedua kelompok

\begin{tabular}{|c|c|c|c|c|c|}
\hline \multirow{2}{*}{ Variabel } & \multicolumn{2}{|c|}{ Ondansetron } & \multicolumn{2}{|c|}{ Midazolam } & \multirow[b]{2}{*}{$p$} \\
\hline & $\mathbf{n}$ & $\%$ & $\mathbf{n}$ & $\%$ & \\
\hline Laki-laki & 7 & 29.20 & 5 & 20.80 & \\
\hline Perempuan & 17 & 70.80 & 19 & 79.20 & 0.505 \\
\hline Total & 24 & 100 & 24 & 100 & \\
\hline
\end{tabular}

Uji Chi - square, bermakna bila nilap $\mathrm{p}<0,05$

Tabel 3. Perbandingan sebaran ASA PS pada kedua kelompok

\begin{tabular}{|c|c|c|c|c|c|}
\hline \multirow{2}{*}{ Variabel } & \multicolumn{2}{|c|}{ Ondansetron } & \multicolumn{2}{|c|}{ Midazolam } & \multirow{2}{*}{$p$} \\
\hline & $\mathbf{n}$ & $\%$ & $\mathbf{n}$ & $\%$ & \\
\hline ASA PS 1 & 4 & 16.7 & 5 & 20.8 & \\
\hline ASA PS 2 & 20 & 83.3 & 19 & 79.2 & 0.712 \\
\hline Total & 24 & 100 & 24 & 100 & \\
\hline
\end{tabular}

Uji Chi - square, bermakna bila nilap $\mathrm{p}<0,05$

Tabel 4. Perbandingan rerata kebutuhan fentanyl pada kedua kelompok

\begin{tabular}{cccccccc}
\hline \multirow{2}{*}{ Variabel } & \multicolumn{3}{c}{ Ondansetron } & \multicolumn{4}{c}{ Midazolam } \\
& n & Mean & SD & n & Mean & SD & $\boldsymbol{p}$ \\
\hline $\begin{array}{c}\text { Kebutuhan } \\
\text { fentanyl }\end{array}$ & 2 & 246.67 & 67.545 & 2 & 251.25 & 57.128 & \multirow{2}{*}{0.801} \\
\hline
\end{tabular}

Uji $\mathrm{T}$ test, bermakna bila nilai $\mathrm{p}<0,05$ 
aktivitas neuronal dopaminergik dan pelepasan serotonin antagonis (5-HT3) dengan berikatan terhadap reseptor dari gamma-aminobutyric acid (GABA). ${ }^{26,32}$

Midazolam juga menghasilkan anxiolisis dalam aplikasinya sebagai efek sekunder yang berkonstribusi sebagai anti emesis. Midazolam menurunkan input psikis dari thalamus yang dapat mempengaruhi secara langsung terhadap pusat muntah.Van Den Bosch dkk (2005) menyatakan bahwa kecemasan pada periode perioperatif mempengaruhi angka kejadian PONV. Selain itu, penurunan sekresi 5-HT3 terjadi setelah midazolam berikatan dengan reseptor GABA. ${ }^{32}$

Midazolam juga mempunyai sejumlah efek samping yang dikaitkan dengan penggunaannya.

Midazolam menurunkan konsumsi oksigen serebral, aliran darah otak dan menurunkan tekanan intrakranial. Aplikasinya berhubungan dengan pemulihan kesadaran yang cenderung lebih lama. Pemanjangan sedasi dapat terjadi sebagai efek potensiasi ketika aplikasi bersama golongan opioid. Hipotensi,

Tabel 9. Perbandingan sebaran skor PONV pada kedua kelompok

\begin{tabular}{|c|c|c|c|c|c|c|c|c|c|c|c|c|}
\hline \multirow{3}{*}{\multicolumn{2}{|c|}{ Kelompok }} & \multicolumn{10}{|c|}{ Skor PONV } & \multirow{3}{*}{$P$} \\
\hline & & \multicolumn{2}{|c|}{ Skor 0} & \multicolumn{2}{|c|}{ Skor 1} & \multicolumn{2}{|c|}{ Skor 2} & \multicolumn{2}{|c|}{ Skor 3} & \multicolumn{2}{|c|}{ Total } & \\
\hline & & $\mathbf{n}$ & $\%$ & $\mathbf{n}$ & $\%$ & $\mathbf{n}$ & $\%$ & $\mathbf{n}$ & $\%$ & $\mathbf{n}$ & $\%$ & \\
\hline \multirow{2}{*}{$\mathrm{P} 1$} & Ondansetron & 20 & 83.3 & 1 & 4.2 & 0 & 0 & 3 & $\begin{array}{c}12 . \\
5\end{array}$ & 24 & 100 & \multirow{2}{*}{$\begin{array}{c}0.36 \\
8\end{array}$} \\
\hline & Midazolam & 20 & 83.3 & 3 & $\begin{array}{c}12 . \\
5\end{array}$ & 0 & 0 & 1 & 4.2 & 24 & 100 & \\
\hline \multirow{2}{*}{$\mathrm{P} 2$} & Ondansetron & 18 & 75 & 6 & 25 & 0 & 0 & 0 & 0 & 24 & 100 & 0.02 \\
\hline & Midazolam & 23 & 95.8 & 0 & 0 & 1 & 4.2 & 0 & 0 & 24 & 100 & $2 *$ \\
\hline \multirow{2}{*}{ P3 } & Ondansetron & 22 & 91.7 & 1 & 4.2 & 0 & 0 & 1 & 4.2 & 24 & 100 & 0.51 \\
\hline & Midazolam & 22 & 91.7 & 2 & 8.3 & 0 & 0 & 0 & 0 & 24 & 100 & 3 \\
\hline \multirow{2}{*}{ P4 } & Ondansetron & 23 & 95.8 & 1 & 4.2 & 0 & 0 & 0 & 0 & 24 & 100 & 0.31 \\
\hline & Midazolam & 24 & 100 & 0 & 0 & 0 & 0 & 0 & 0 & 24 & 100 & 2 \\
\hline \multirow{2}{*}{ P5 } & Ondansetron & 23 & 95.8 & 0 & 0 & 0 & 0 & 1 & 4.2 & 24 & 100 & 0.31 \\
\hline & Midazolam & 24 & 100 & 0 & 0 & 0 & 0 & 0 & 0 & 24 & 100 & 2 \\
\hline \multirow{2}{*}{ P6 } & Ondansetron & 23 & 95.8 & 1 & 4.2 & 0 & 0 & 0 & 0 & 24 & 100 & 1.00 \\
\hline & Midazolam & 23 & 95.8 & 1 & 4.2 & 0 & 0 & 0 & 0 & 24 & 100 & 0 \\
\hline \multirow{2}{*}{$\mathrm{P} 7$} & Ondansetron & 24 & 100 & 0 & 0 & 0 & 0 & 0 & 0 & 24 & 100 & 0.31 \\
\hline & Midazolam & 23 & 95.8 & 0 & 0 & 1 & 4.2 & 0 & 0 & 24 & 100 & 2 \\
\hline \multirow{2}{*}{ P8 } & Ondansetron & 24 & 100 & 0 & 0 & 0 & 0 & 0 & 0 & 24 & 100 & 0.31 \\
\hline & Midazolam & 23 & 95.8 & 1 & 4.2 & 0 & 0 & 0 & 0 & 24 & 100 & 2 \\
\hline
\end{tabular}


Tabel 10. Perbandingan sebaran skor sedasi pada kedua kelompok

\begin{tabular}{|c|c|c|c|c|c|c|c|c|c|c|c|c|c|c|}
\hline & \multirow{3}{*}{ Kelompok } & \multicolumn{12}{|c|}{ Skor Sedasi } & \multirow{3}{*}{$P$} \\
\hline & & \multicolumn{2}{|c|}{ Skor 1} & \multicolumn{2}{|c|}{ Skor 2} & \multicolumn{2}{|c|}{ Skor 3} & \multicolumn{2}{|c|}{ Skor 4} & \multicolumn{2}{|c|}{ Skor 5} & \multicolumn{2}{|c|}{$\begin{array}{c}\text { Skor } \\
6\end{array}$} & \\
\hline & & $\mathbf{n}$ & $\%$ & $\mathbf{n}$ & $\%$ & $\mathbf{n}$ & $\%$ & $\mathbf{n}$ & $\%$ & $\mathbf{n}$ & $\%$ & $\mathbf{n}$ & $\%$ & \\
\hline \multirow{2}{*}{ P1 } & Ondansetron & 3 & 12.5 & 19 & 79.2 & 2 & 8.3 & 0 & 0 & 0 & 0 & 0 & 0 & \multirow{2}{*}{0.158} \\
\hline & Midazolam & 0 & 0 & 20 & 83.3 & 4 & 16.7 & 0 & 0 & 0 & 0 & 0 & 0 & \\
\hline \multirow{2}{*}{ P2 } & Ondansetron & 2 & 8.3 & 21 & 87.5 & 1 & 4.2 & 0 & 0 & 0 & 0 & 0 & 0 & \multirow{2}{*}{0.148} \\
\hline & Midazolam & 0 & 0 & 20 & 83.3 & 4 & 16.7 & 0 & 0 & 0 & 0 & 0 & 0 & \\
\hline \multirow{2}{*}{ P3 } & Ondansetron & 0 & 0 & 24 & 100 & 0 & 0 & 0 & 0 & 0 & 0 & 0 & 0 & \multirow{2}{*}{0.074} \\
\hline & Midazolam & 0 & 0 & 21 & 87.5 & 3 & 12.5 & 0 & 0 & 0 & 0 & 0 & 0 & \\
\hline \multirow{2}{*}{ P4 } & Ondansetron & 0 & 0 & 24 & 100 & 0 & 0 & 0 & 0 & 0 & 0 & 0 & 0 & \multirow{2}{*}{0.312} \\
\hline & Midazolam & 0 & 0 & 23 & 95.8 & 1 & 4.2 & 0 & 0 & 0 & 0 & 0 & 0 & \\
\hline
\end{tabular}

\section{DAFTAR PUSTAKA}

agitasi, restlessness, drowsiness, takikardi, amnesia anterograde, eksitasi psikomotor dan depresi nafas merupakan sejumlah komplikasi yang dapat terjadi. Aplikasi midazolam intranasal, dapat menimbulkan iritasi dibanding obat lain ketika diberikan dengan rute yang sama. Pada pasien usia lanjut, mempunyai sensitifitas tinggi terhadap aplikasi midazolam. ${ }^{9,10,33}$

\section{SIMPULAN}

Midazolam $35 \mu \mathrm{g} / \mathrm{kgBB}$ setelah premedikasi pada anestesi umum pada prosedur pembedahan laparaskopi elektif menurunkan kejadian mual muntah pascabedah terutama pada 1 jam pasca bedah.
1. Islam S, Jain PN. Post operative nausea and vomiting (PONV): a review article. Indian J Anaesth. 2004; 48 (4):253-58.

2. Cracken GM, Houston P, Lefebvre G. Guidline for the management of postoperative nausea and vomiting. SOGC Clinical Practice Guidline. 2008 July.

3. Apfel CC, Laara E, Koivuranta M, Greim CA, Roewer N. A simplified risk score for predicting postoperative nausea and vomiting. American $S$ of Anaesth. 1999; 91:693-700.

4. Licthor JL, Kalghatgi SV. Outpatient anesthesia. In: Longnecker DE, Brown DDL, Newman MF, Zapol WM, editors. Anesthesiology. New York: Mc Graw Hill; 2008. p.1608-19.

5. Gerges FJ, Kanazi GE, Jabbour-khoury SI. Anesthesia for laparoscopic. J Clin Anesth 2006; 18: 67-68.

6. Ali Z, Ahmad T, Ahmad I. Preoperative dexamethasone in laparoscopic cholecystectomy patients. J Professional 
Med. 2010; 3:394-99.

7. Habib SA, Gan TJ. Evidence based management of postoperative nausea and vomiting. Can J Anaesth. 2004; 51:32641 .

8. Stoelting Rk, Hillier SC. Benzodiazepin. In: Pharmacology \& physiology in anesthetic practice. $4^{\text {th }}$ Edition. Philadelphia: Lippincott Williams \& Wilkins; 2006. p.104-8.

9. Rodola F. Midazolam as an antiemetic. Europ Rev for Medical and Pharmacological Sciences. 2006; 10:121-6.

10. Polati E, Verlato G, Finco G, Mosaner W, Grosso S, Gottin L, et al. Ondansetron versus metoclopramid in the treatment of postoperative nausea and vomiting. Anesth Analg. 1997; 85:395-9.

11. Riad W, Marouf H. Combination theraphy in the prevention of PONV after strabismus surgery in children: granisetron, ondansetron, midazolam and dexamethason. MEJ Anaesth. 2009; 20(3):431 -36 .

12. Sanjay OP, Tauro DI. Midazolam: an effective antiemetic after cardiac surgerya clinical trial. Anesth Analg. 2004; 99:339-43.

13. Safavi MR, Honarmand A. Low dose intravenous midazolam for prevention of PONV in lower abdominal surgery. $M E J$ Anaesth. 2009; 20(1):75-82.

14. Jang JS, Lee JH, Lee JJ, Park WJ, Hwang SM, Lee SK, Lim SY. Postoperative nausea and vomiting after myringoplasty under continous sedation using midazolam with or without remifentanyl. Yonsei Med J. 2012; 53(5):1010-13.

15. Kim DS, Koo GH, Baek CW, Jung YH, Woo YC, Kim JY, Park SG. The antiemetic effect of midazolam or/and ondansetron added to intravenous patient controlled analgesia in patients of pelviscopic surgery. Korean J Anesthesiol. 2012; 62(4):343-49.

16. Becker DE. Nausea, vomiting, and hiccups: a review of mechanism and treatment. Anesth Prog. 2010; 57:15057.

17. Chandrakantan W, Glass PS. Multimodal therapies for postoperative nausea and vomiting, and pain. Brt $J$ Anaesth. 2010; 107:i27-i40.

18. Aitkenhead AR, Smith G, Rowbotham DJ, editors. Postoperative nausea and vomiting. In: Textbook of anaesthesia. 5th Edition. Edinburgh: 2007; p.526-32.

19. Apfel CC, Kranke P, Eberhart LH, Roos A, Roewer N. Comparison of predictive models for postoperative nausea and vomiting. Brt J Anaesth. 2002; 88: 23440.

20. Gan TJ, Meyer T, Apfel CC. Society for ambulatory anesthesia guidelines for the management of postoperative nausea and vomiting. Anesth Analg 2007; 105:161527.

21. Riad W, Altaf R, Abdulla A, Oudan H. Effect of midazolam, dexamethasone and their combination on the prevention of nausea and vomiting following strabismus repair in children. Europ $J$ of Anaesth. 2007; 24:697-701.

22. White PF, Sacan O, Nuangchamnong N, Sun T. The relationship between patient risk factors and early versus late postoperative emetic symptoms. Anesth Analg. 2008; 107: 459-63.

23. Scuderi P, Salem W. Postoperative nausea and vomiting: prevention and treatment. Can J Anaesth 2002; 49:241-46.

24. Stadler M, Bardiau F, Seidel L, Albert 
A, Boogaerts JG. Difference in risk factors for postoperative nausea and vomiting. Anesthesiology. 2008; 58 (4):203-5.

25. Crozier TA. Anaesthesia for laparoscopic surgery. In: Anaesthesia for minimally invasive surgery. Cambridge: Cambridge University Press; 2004. p.55-70.

26. Park EY, Lee SK, Kang MH, Lim KJ, Kim YS, Choi E, Park YH. Comparison of ramosetron with combined ramosetron and midazolam for preventing postoperative nausea and vomiting in patient at high risk following laparascopic gynaecological surgery. J of International Med Research. 2013; 0(0):1-10.

27. Wang S, Joseph G, Martin F. Evaluation of three 5-HT3 receptor antagonists in the prevention of postoperative nausea and vomiting in adults. P\&T 2005; 30: 34153.

28. Farid RM. Perbandingan efektifitas ondansetron dan metoclopramid dalam menekan mual muntah pasca operasi pada pembedahan perut bawah kasus ginekologi. Anesth and Crit Care. 2005; 23:127-32.

29. Habib AS, Reuveni J, Taguchi A, White
WD, Gan TJ. A comparison of ondansetron with promethazine for treating postoperative nausea and vomiting in patients who received prophylaksis with ondansetron: a retrospective database analysis. Anesth Analg. 2007; 104:548-51.

30. Kasinath NS, Malak O, Tetzlaff J. A case report: Atrial fibrillation after ondansetron for the prevention and treatment of postoperative nausea and vomiting. Can J Anaesth. 2003; 50:228-31.

31. Shahriari A, Khooshideh M, Heidari MH. Prevention of nausea and vomiting in cesarean section under spinal anaesthesia with midazolam or metoclopramide?. $J$ Pak Med Assoc. 2009; 59(11):756-59.

32. Alstrup AKO, Simonsen M, Landau AM. Type of anesthesia influences positron emission tomography measurements of dopamine D2/3 receptor binding in the rat brain. Scand J Lab Anim Sci. 2011; 38 (3):195-201.

33. Tang J, Wang B, White PF, Gold M. Comparison of the sedation and recovery profiles of Ro 48-6791, a new benzodiazepine and midazolam in combination with meperidine for outpatient endoscopic procedures. Anesth Analg. 1999; 89:8938. 